\title{
DETERMINATION OF DIVERSE ENVIRONMENTAL POLLUTION LEVEL FROM SELECTED AREAS OF RAWALPINDI, PAKISTAN
}

\author{
S. Pervezl,*, M. S. Siddiquel, H. Y. Abdullah', A. Zahra', N. K. khanzadal', H. Fareed', G. Hasnain' \\ 1. Institute of Environmental Sciences and Engineering, National University of Sciences and Technology (IESE, NUST), Islamabad \\ 2. School of Natural Sciences, National University of Sciences and Technology (SNS, NUST), Islamabad
}

\begin{abstract}
Anthropogenic contaminants arising from both stationary (power plants, industries and residential heating) and mobile sources (road traffic) can harm ambient air quality in urban areas. Depending upon their physical state, these pollutants are classified as liquid and vapor phases and are subsequently transported to the Earth's surface through dry and wet deposition. After the deposition of these pollutants onto the surface of earth various health effects caused by these pollutants occurred like cardiovascular diseases and hypertension. In this study four different locations/sites were selected from the Rawalpindi city depending upon the population, traffic rush and industries to examine the noise level, concentration of carbon dioxide and heavy metals. Air sampler was used for the collection of air sample to analyze the heavy metal concentration, Quest electronic sound meter for measuring sound level and SIBATA for $\mathrm{CO}_{2}$ measurement. The study findings revealed that noise level was higher at all selected locations as described by WHO limit (70 dB) being highest at Industrial area due to heavy machinery and lowest at green area. Concentration of all four heavy metals were high as compared with the prescribed limits. $\mathrm{CO}_{2}$ level reaches up to 300 ppm because of coal consumption during the winter season. The threshold values of all these selected parameters well above the prescribed limits defined by the authorities so to combat with this situation we should move towards more energy efficient fuels, proper maintenance of vehicles and machineries, traffic management and installation of noise barriers in industries as well as installation of catalytic convertors in vehicles to stop further air pollution.
\end{abstract}

KEYWORDS: Climate change, Heavy metals, $\mathrm{CO}_{2}$, Noise, Rawalpindi

*Corresponding author: (Email: saim3035@gmail.com)

\section{INTRODUCTION}

Pakistan is bestowed with a great diversity of landscape, climate, seasons, ecosystems, etc. The landscape ranges from snowcapped peaks in the Himalayan Range in the north to Arabian Sea coastline in the south, from agriculture ranges in the plains to hot dry deserts in Sindh and Baluchistan. This diversity has given rise to a variety of living organisms including flora, fauna, animals, birds, insects, etc. which provide economic 
benefits and services to human society as well as ecological, recreational, cultural and aesthetic values.

However, this diversity provided by the nature has not been exempted by the human greed for development, has been to a large extent exploiting the variety of resources provided by the nature. Although Pakistan contributes only 0.8 percent in the global greenhouse gas emissions and is ranked 135th in global GHG per capita emissions, still the countries biodiversity is prone to adverse impacts of climate change and the country has been rated as one of the most vulnerable nations to the adverse effects of climate change.

Sources of air pollution are: (1) Natural (2) manufactured. Natural sources includes wind storms, volcanic ash and gases, pollens and gases or odors from natural decomposition while man-made sources of air pollution are: industries and vehicles (ElMubarak et al., 2014). The main pollutants from all these sources are carbon dioxide (CO2), methane $(\mathrm{CH} 4)$, hydrocarbons and particulate matter. Two different types of air pollutants are present, Primary and secondary pollutant. Primary pollutants are those that occurs in a harmful concentration, added directly to the air by natural events or human activities while secondary pollutants are formed in atmosphere when a primary pollutant reacts with the normal air components or with other air pollutants. [1]. Effects of all these man-made or natural atmospheric pollutants are very adverse like severe respiratory problems such as asthma, chronic bronchitis, and degraded lung function and at last but not least respiratory failure $[2,3]$.
So, it is necessary to combat with all these types of pollutants and with the sources, that a healthier environment could achieve and climate change not affect at all. The aim of the present study is to analyze and characterize the ambient air of Rawalpindi city for the quantitative assessment of heavy metals, noise level and carbon dioxide emissions from anthropogenic sources and examine the current level of compliance with environmental regulations.

\section{MATERIALS AND METHODS}

The present study deals with the characterization and analysis of ambient air of Rawalpindi city. For this analysis, four different locations based upon populations and industrial density were selected. Bahria town was selected as residential area while commercial market selected as a commercial area. Murree road is one of the congested and busy road of Rawalpindi city and also industries lies on the side of the road hence it was selected as industrial area whereas Ayub Park selected as green area. Air samples were collected from December to February.

A brief methodology followed during the project was:

1. Selection of the area

2. Visiting the sites

3. Taking the readings of noise and $\mathrm{CO}_{2}$

4. Collecting the air samples

5. Obtaining the heavy metals measurements using the AAS.

6. Comparing the values with standards

The analysis of different parameters measured were performed using standard 
methods by APHA (American Public Health Association) 2010 as reference.

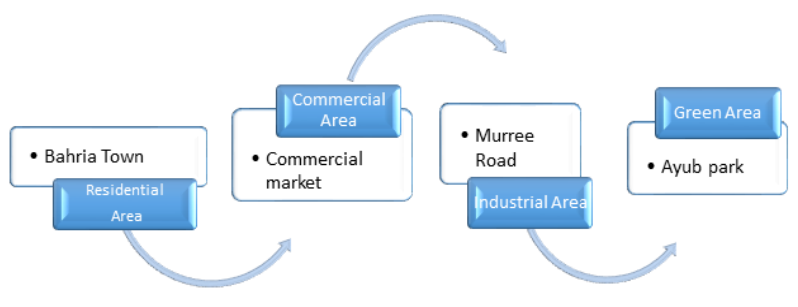

Figure 1. Selection of the areas

\subsection{Measurement of Noise Level}

For noise measurement the standard method was used as described in the literature. Instrument that was used named as Quest electronic sound meter (model 211 fs). First of all turn on the meter, select $100 \mathrm{~dB}$ range position then switch on the calibrator and check battery level indicator, carefully insert the meter microphone into the calibrator coupler. If reading is off slightly, insert a small screwdriver in the small hole on the bottom of the meter. Now change the selector switch to $110 \mathrm{~dB}$ position on the meter and note the needle should drop to the zero position on the meter dial. Meter is now calibrated and ready for use. Allow the needle to stabilize and record the measurement. (APHA, 2010)

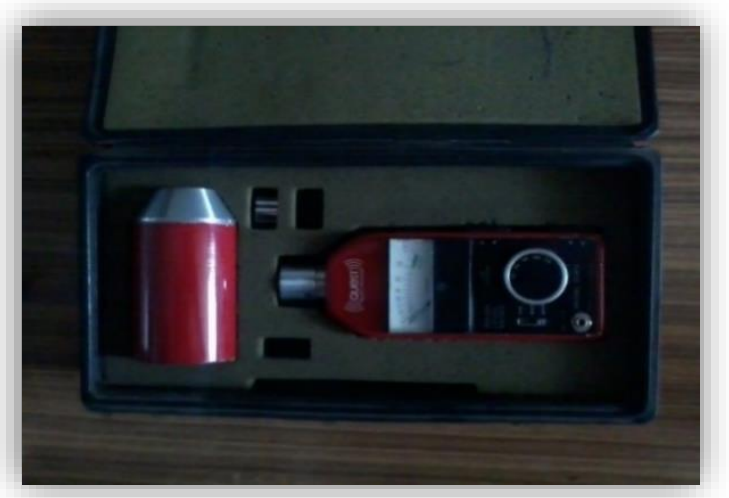

Figure 2. Quest electronic sound meter

\subsection{Measurement of Carbon Dioxide (CO2)}

$\mathrm{CO}_{2}$ in air was monitored using combustion Gas Analyzer (US). The $\mathrm{CO}_{2}$ value was monitored and average was calculated. The sound level was monitored with the help of a portable sound meter. The equipment was mounted on a tripod stand with a microphone $1.5 \mathrm{~m}$ above the ground level. The data was continuously monitored and average values were calculated. (APHA, 2010)

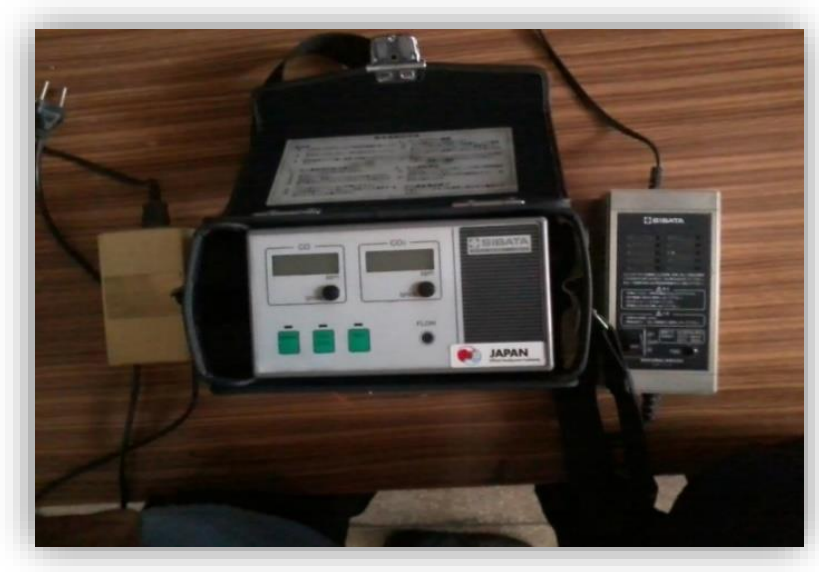

Figure 3. SIBATA $\mathrm{CO}_{2}$ meter

\subsection{Air Samples for Heavy Metals Determination}

Pall flex quartz fiber filter was used for air sampling which was preheated at $550^{\circ} \mathrm{C}$ for 1 hour. It was then mounted on an air sampler for 2 hours and air flow was kept at $1 \mathrm{~m}^{3} / \mathrm{min}$. After sampling, the paper was stored in aluminum foil and stored in freezer till analysis. Heavy metals were determined by chemically digesting filter paper and the resulting solution analyzed using AAS (atomic absorption spectrometer) [4]. 


\section{RESULTS AND DISCUSSION}

Results and discussion were made according to the survey of the selected areas and after the calculation of the desired pollutant level.

\subsection{Noise Level at Selected Sites of Study Area}

The noise level determined using the sound meter at all the selected locations and found it to be that at location of Ayub Park which is declared as green area has the minimum level of $78 \mathrm{~dB}$ while the residential area and commercial area both have the same value of noise level i.e. $90 \mathrm{~dB}$ although commercial area has more average value which is because of excessive vehicle horn and heavy traffic jam [5]. The value of sound was higher at industrial area i.e. $80-90 \mathrm{~dB}$ because of heavy machinery working and industrial plants. The noise level at all the selected locations was greater than the prescribed limits given by world health organization (WHO). Chronic exposure of this loud noise level cause problems like cardiovascular and hypertension [6].

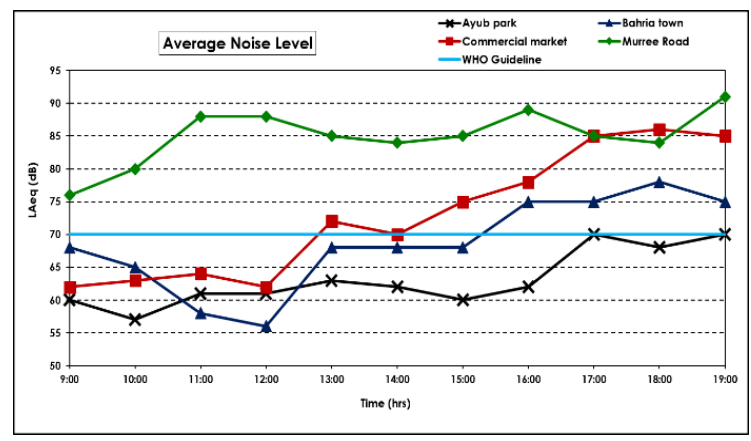

Figure 4. Average of Noise level (dB)

\subsection{Carbon Dioxide Concentration at Selected Locations}

Because of anthropogenic activities, CO2 concentration was up to 300ppm. Max average value was observed at Bahria town i.e. 238 ppm while minimum average value was noted at commercial market. Murree road and Ayub Park had the average values of 214 and 207 ppm respectively. Astonishingly the area expected to have minimum pollution levels i.e. residential area of Ayub Park had maximum average values observed. This was probably winds blowing that took high concentrations of $\mathrm{CO}_{2}$ from congested areas like commercial markets to residential areas like Bahria town [7]. Moreover highest values were observed at 1 : 00 PM and 7: 00 PM because these are the peak hours having maximum traffic population. Pakistan is one of top 50 countries in terms of $\mathrm{CO}_{2}$ emissions [8].

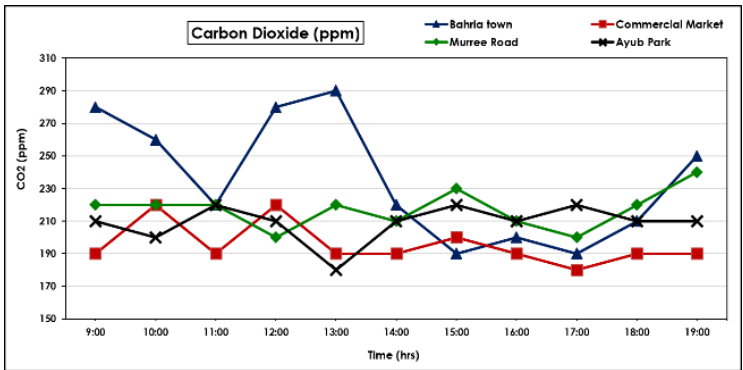

Figure 5. Average of Carbon Dioxide (CO2) concentration (ppm)

\subsection{Heavy Metals Concentrations}

\subsubsection{Lead}

Maximum concentration was observed at Bahria town i.e. $149 \mu \mathrm{g} / \mathrm{m}^{3}$ while minimum at Ayub park i.e. $63 \mu \mathrm{g} / \mathrm{m}^{3}$.there are two main sources of lead, lower quality fuel combustion and lead based paints [9]. Both of these sources are absent in Ayub park 
that's why it has minimum concentration while in residential area paints and use of fuel in generators for electricity purpose are the source that's why it has maximum values. All values are exceeding WHO guidelines of 0.5 $\mathrm{\mu g} / \mathrm{m}^{3}$ which is alarming because lead is very harmful for human health mainly damage to nervous system even leading to death [10].

\subsubsection{Chromium}

Maximum concentration was observed at commercial market i.e. $42 \mu \mathrm{g} / \mathrm{m}^{3}$ while minimum at Ayub park. All the values are exceeding $\mathrm{WHO}$ guidelines for $0.11 \mathrm{\mu g} / \mathrm{m}^{3}$. Chromium is build up in atmosphere when there is lack of winds and air congestion. As commercial market was congested area so there was lack of winds in area which results in chromium buildup due to pollution in area. When there is good wind it is readily diluted. Chromium in air can lead to lung cancer [1 1].

\subsubsection{Arsenic}

Maximum value was observed at commercial market i.e. $33 \mu \mathrm{g} / \mathrm{m}^{3}$ Main sources of arsenic are fuel combustion and metal smelting and aerosols from pesticide. Welding shops lead to smelting while pesticides are used in parks adding to fuel combustion of vehicles. All the values are exceeding guidelines of WHO i.e. $0.11 \mu \mathrm{g} / \mathrm{m}^{3}$. This should be taken as important concern because arsenic is very poisonous for human health [12].

\subsubsection{Iron}

All the values were exceeding the standards set by WHO for iron in air i.e. 150 $\mu \mathrm{g} / \mathrm{m}^{3}$. Highest values were obtained at commercial market and Murree road i.e. 376 and $512 \mu \mathrm{g} / \mathrm{m}^{3}$ respectively. Sources were use of old machinery, dust winds and local industrial area [13].

\subsubsection{Manganese}

Manganese concentration were lowest among all the heavy metals detected but it was still higher than WHO standards i.e. 0.15 $\mathrm{\mu g} / \mathrm{m}^{3}$.highest levels were obtained at Murree road i.e. $162 \mathrm{\mu g} / \mathrm{m}^{3}$ and lowest levels were detected at Ayub park i.e. $3 \mu \mathrm{g} / \mathrm{m}^{3}$. Sources of manganese are production of steel and alloys and burning of fossil fuels that's why it has maximum concentration at Murree road. [4]. its chronic exposure can cause neurological disorders [14].

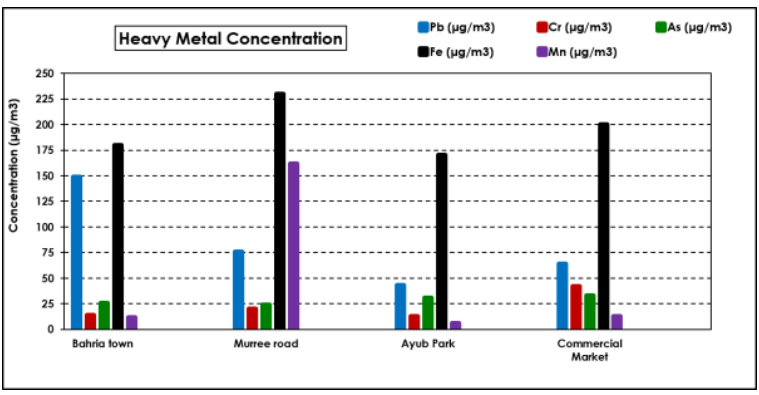

Figure 6. Average concentration of heavy metals

\section{CONCLUSIONS}

It was observed that almost all the values for heavy metals and noise were found to be exceeding the WHO guidelines that is very alarming situation for the city environment and its inhabitants. Poisonous and dangerous heavy metals such as Arsenic (peak value: 33 $\mathrm{\mu g} / \mathrm{m}^{3}$, WHO limit: $0.11 \mu \mathrm{g} / \mathrm{m}^{3}$ ), Lead (peak value: $149 \mu \mathrm{g} / \mathrm{m}^{3}$, WHO limit: $0.50 \mu \mathrm{g} / \mathrm{m}^{3}$ ) and Chromium (peak value: $42 \mu \mathrm{g} / \mathrm{m}^{3}$, WHO limit: $\left.0.11 \mathrm{mg} / \mathrm{m}^{3}\right)$ are more than 10 times their guideline values. Average Noise levels were around $80-90 \mathrm{db}$ whereas safe hearing limit is 
below $85 \mathrm{db}$. CO2 values (300 ppm) were although in bearable limit but it is a greenhouse gas so this average amount of CO2 may be significant for our global temperature rise.

\section{References}

[1] H. Peace, B. Owen, D.W. Raper, Comparison of road traffic emission factors and testing by comparison of modelled and measured ambient air quality data, Sci. Total Environ 334-335 (2004) 385-395.

[2] M. Mansha, B. Ghauri, S. Rahman, A. Amman, Characterization and source apportionment of ambient air particulate matter (PM2.5) in Karachi, Sci Total Environ 425 (2012) 176-183.

[3] C. Y. Yang, Y. S. Chen, C. H. Yang, S. C. Ho, Relationship between ambient air pollution and hospital admissions for cardiovascular diseases in Kaohsiung, Taiwan, J. Toxicol. Environ. Health A, 67 (2004) 483-93.

[4] A. A. Gharaibeh, A.W. El-Rjoob, M.K. Harb, Determination of selected heavy metals in air samples from the northern part of Jordan, Environ. Monit. Assess 60 (2010) 425-429.

[5] M. Ali, and M. Athar, Impact of transport and industrial emissions on the ambient air quality of Lahore City, Pakistan, Environ Monit. Assess 171 (2010) 353-363.

[6] B. Berglund, T. Lindvall, D.H. Schwela, Guidelines for Community Noise, World Health Organization (1999).

[7] S. Rogers, L. Evans, World carbon dioxide emissions data by country: China speeds ahead of the rest, The Guardian, (2011).

[8] P. Dalal, D. Chaudhry, V. Shukla, Analysis of heavy metals concentration in ambient air and in human population of Rohtak, India, J Env. Biol 34 (2013) 945-949.

[9] WHO, Air Quality Guidelines World Health Organization, 2nd Edition, (2000).
[10] Y. M. Coyle, A. T Minahjuddin, L. S. Hynan, J. D Minna, An ecological study of the association of metal air pollutants with lung cancer incidence in Texas, J Thorac. Oncol 7 (2006) 654-661.

[11] E. Von Schneidemesser, E. A. Stone, T. A. Quraishi, M.M. Shafer, J. J. Schaver, Toxic metals in the atmosphere in Lahore, Pakistan, Sci Total Environ, 408 (2010) 1640-1648.

[12] A. H. El-Mubarak, A. I. Rushdi, k. F. Al-Mutlaq, A. Y. Bazeyad, S. L Simonich, B. R Simoneit, Identification and source apportionment of polycyclic aromatic hydrocarbons in ambient air particulate matter of Riyadh, Saudi Arabia, Environ Sci. Pollut. Res. Int 21 (2014) 558-567.

[13] R. J. Delfino, J. Wu, T. Tjoa, S. K. Gullesserian, B. Nickerson, D.L. Gillen, Asthma morbidity and ambient air pollution: effect modification by residential traffic-related air pollution, Epidemiology 25 (2014) 48-57.

[14] Y. Gao, E. Y Chan, L. Li, P. W Lau, T. W Wong, Chronic effects of ambient air pollution on respiratory morbidities among Chinese children: a cross-sectional study in Hong Kong, BMC Public Health 14 (2014) 105.

[15] D. Ware, J. Lewis, S. Hopkins, B. Boyer, C. Noonan, T. Ward, Sources and perceptions of indoor and ambient air pollution in rural Alaska, J Community Health 38 (2013) 773780.

[16] G. C. Rhoderick, 2013, The National Institute of Standards and Technology ambient level methane in air Standard Reference Material historical record, Anal Bioanal. Chem, 405 (2013) 369-375.

[17] H. H. Kim, C. S. Lee, J. M. Jeon, S. D. Yu, C. W. Lee, J. H. Park, D.C Shin, Y. W Lim, Analysis of the association between air pollution and allergic diseases exposure from nearby sources of ambient air pollution within 
elementary school zones in four Korean cities, Environ. Sci. Pollut. Res. Int 20 (2013) 48314846.

[18] M. J. Strickland, K. M. Gass, G. T. Goldman, J. A. Mulholland, Effects of ambient air pollution measurement error on health effect estimates in time-series studies: A simulationbased analysis, J Expo. Sci. Environ. Epidemiol 25 (2013) 160-166.

[19] S. Kumar, M. K. Verma, and A. K Srivastava, ultrafine particles in urban ambient air and their health perspectives, Rev. Environ. Health 28, (2013) 117-128.

[20] S. M. Garcia, G. Domingues, C. Gomes, A. V. Silva, S. M. Almeida, Impact of road traffic emissions on ambient air quality in an industrialized area, J. Toxicol. Environ. Health A 76 (2013)429-439.

[21] N. E. Latysh, G. A. Wetherbee, Improved mapping of National Atmospheric Deposition Program wet-deposition in complex terrain using PRISM-gridded data sets, Environ. Monit. Assess 184 (2012) 913-928.
[22] M. E. Fragala, Y. Aleeva, C. Satriano, Integration of metal organic chemical vapor deposition and wet chemical techniques to obtain highly ordered porous $\mathrm{ZnO}$ nanoplatforms, J. Nanosci. Nanotechnology 11 (2011) 8180-8184.

[23] J. P. Schoonmaker, A. H. Trenkle, D. C. Beitz, Effect of feeding wet distillers grains on performance, marbling deposition, and fatty acid content of beef from steers fed low or high-forage diets, J. Anim. Sci 88 (2010) 3657 3665.

[24] M. Anicic, M. Tomasevic, M. Tasic, S. Rajsic, A. Popovic, M.V. Frontasyeva, S. Lierhagen, and E. Steinnes, Monitoring of trace element atmospheric deposition using dry and wet moss bags: Accumulation capacity versus exposure time, J Hazard. Mater 171 (2009) 182-188.

[25] NIOSH, NIOSH Regulations and Guidelines (2003).

[26] R. J. Thompson, G. B. Morgan, L. J. Purdue, Analysis of Metallic Air Pollutants, At. Absorpt. Newsl. 9 (1970) 195.

[27] B. Mason, Principles of geochemistry, 3th edition, John Wiley and Sons, (1966). 